\section{Peking University's Personnel Reforms}

\section{RUI YANG}

Rui Yang is director and associate professor at the Comparative Education Research Centre, University of Hong Kong, Pokfulam Road, Hong Kong. Email: yangrui@hkucc.hku.hk.

A iming to rank among the world's best universities, in 2004 Peking University planned a radical overhaul of its faculty appointment and promotion policies. The reform program went far beyond the sphere of personnel itself and received a strong response not only on campus but throughout the country. Widely cited as a weather vane for Chinese higher education reform, the developments have vividly portrayed the difficulties and obstacles in China's new policies for universities in a context of globalization and helped to identify further directions and dynamics.

\section{The Range of Causes}

A number of contextual factors have exerted impact on the reform plan. With ascending neoliberal thinking, market ideologies have burgeoned in China's higher education sector. Chinese universities are opened to increasing public scrutiny and an expansion of expectations by both governments and societies. Meanwhile, the Chinese government is committed to strategically promoting a group of Chinese universities to enter the world-class league within a decade and is investing heavily on them. Through reforming its personnel system, Peking University attempted to have a world-class teaching and research force in order to become a world-class institution.

A more direct reason was financial. During I999-200I, the state granted the university an extra fund of I.8 billion yuan in support of its development. The fund was used to substantially increase the wage of each teacher. While ordinary teachers might find nothing improper in the university's taking the money, their institutional leaders were grilled by the fact that the university must show real achievements if it wanted more money from the central revenue in future. In view of this, the university launched its personnel system reforms to encourage competition and promote the flow of personnel when its highranking academic posts were filled, by and large, and not a single high-paid teacher was willing to leave.

\section{The Reform Plan}

On May I2, 2003, Peking University's drafting committee of the personnel reform working team approved the first draft of its reform proposal. The draft was then released throughout the campus for comment, generating a great deal of controver- sy. Confronted with strong criticism and suggestions from within the university and the wider society, the leading and implementation panels produced a second version of the reform plan for discussion in June, with evident revisions and substantial compromises. The second draft represented a readjustment of interests among different groups, aiming to stabilize the existing teaching force at the university. But the original objective-with the market mechanism used to reform teacher appointment and promotion and the substitution of teachers to obtain a domino effect for restructuring the academic system-ended largely in failure. In April 2004, implementation of the personnel reforms finally began. Although the university claimed that it managed to adhere to the basic principle of the original reform design, the final version was much more moderate. It made a number of concessions and left people with the impression that the plan started with great strength and impetus, but in the end it turned out to only scratch the surface.

With ascending neoliberal thinking, market ideologies have burgeoned in China's higher education sector.

The essence of the reform plan was to open up academic positions. Basic features of the reform plan included: (I) teachers employed and moved to work at different levels of posts; (2) an elimination system to be instituted for different branches of learning that did not have good prospects for development; (3) a competitive mechanism from outside to be introduced for personnel employment and promotion; (4) in principle, no students of Peking University to be directly recruited into the teaching staff upon graduation; (5) posts for teachers to be divided into two kinds: teaching and research, and full-time teaching; and (6) a judge's panel of professors to be set up for teacher employment and promotion.

\section{The Pros-and-Cons Debate}

Shortly after the draft plan was launched, all the six major moves proposed in the draft plan were heavily criticized as well as strongly defended. The reform plan, which may seem commonplace to many in Western universities, aroused such strong concerns given that changes to personnel policy were a crucial part of the reforms, because landing a teaching post at a Chinese university had traditionally been seen as guaranteed lifelong employment.

Most of the supporters of the reform plan were somewhat distant from or completely unrelated to Peking University, while most of those with reservations about the reform plan were directly related to the university. The most concentrated opposition came mainly from humanists and a few social scientists within the university or among its alumni. The sharpest critics asked whether the plan intended to reform or castrate 
the university, an issue seen as a question of life or death concerning China's traditional culture. They raised the matter to the level of principles and accused the reformists of breaking the law.

The reform plan received strong support from other university leaders, such as Zhu Qingshi-president of the University of Science and Technology of China-who saw Peking's policy as pioneering work and wanted to follow suit. The proposal was also well received by higher education experts-including Pan Maoyuan and Yang Dongping, respectively, from Xiamen University and Beijing University of Science and Technology. Ji Baocheng, president of Renmin University, stated that the reform was an important step forward as China's higher education reform reached a critical time. He insisted that reform of the personnel system was the primary reform needed. A similar viewpoint was expressed by Hou Zixin, president of Nankai University.

The most meaningful part of the debate was the notion of the Chinese idea of the university. The argument was that the fundamental mission of Chinese universities must be a judicious combination of learning from Western university traditions and the ideological, intellectual, cultural, and educational independence of the Chinese. The orientation of Chinese university reforms should be toward developing such a mission. Support for this notion appeared on both sides of the debate. The differences lay in practical priorities.

Shortly after the draft plan was launched, all the six major moves proposed in the draft plan were heavily criticized as well as strongly defended.

\section{Realistic Observations}

In marked contrast to the early wide publicity, little discussion has recently been raised about the reforms. Indeed, by the time when the communist China celebrated its 6oth birthday, Peking University personnel reforms had almost fizzled out completely as Peking University President Xu Zhihong departed. Several years have passed since the policy was put into operation, and little difference has been made.

Similar to China's reforms in other major arenas since the I980s, the approach employed by Peking University in its personnel reforms was top-down, expressing mainly official wishes. The reforms were pushed forward at the highest level of the university, designed and orchestrated by economists who had completed their doctorates in major English-speaking countries. Unlike China's previous reforms implemented through administrative power soon after decision making at the central with little room for discussion, Peking University's reforms sought soft-landing and agreement by trying to balance various groups' interests. In this sense, the reforms should be given some credit despite falling short of most of the intended goals.
The reforms extended well beyond the personnel sphere and far outside the university campus, taking in some fundamental issues underlying Chinese higher education development. The responses to the reform plan demonstrated the difficulty of China's university reforms as "the last fortress of a command-and-control society." A number of issues that emerged during the process of Peking University's personnel reforms illustrated China's long-standing struggle to strike a balance between dominant Western models and carrying forward its own rich cultural and educational traditions. The experience reiterated the complexity of the internationalization of Chinese universities.

\section{The Polytechnic Universities in China's Transformation Ruth Hayhoe and Qiang Zha}

Ruth Hayhoe is a professor in the Department of Theory and Policy Studies in Education, Ontario Institute for Studies in Education, University of Toronto, Canada. E-mail: ruth-hayhoe@sympatico.ca. Qiang Zha is an assistant professor in the Faculty of Education, York University, Toronto, Canada.E-mail: qzha@edu.yorku.ca.

P olytechnic postsecondary institutions have a long history. France was the first nation to raise engineering to the status of a learned discipline, with the creation of the Ecole Polytechnique in I794, shortly after the French Revolution. The status of this and other grandes écoles in the French higher education system was clearly higher than that of the traditional universities. This was in striking contrast to the position given to Germany's Technische Hochschule in the early igth century, although some attained the same status as universities later in the century. The Soviet Union went somewhat further than either France or Germany in elevating the polytechnical university to a leading role in the socialist higher education system. It served well a system of macrosocial and macroeconomic planning that slotted all varieties of engineering expertise into clearly designated professional and geographical sectors.

\section{Polytechnic Universities in China}

When China adopted Soviet patterns for higher education after the revolution of I949, it was not surprising to see the percentage of engineering enrollments rise from I5 percent to 36.5 percent by I960, and to see highest status and prestige accorded to polytechnic and specialist engineering universities. Institutions such as Tsinghua in Beijing and Zhejiang 